\title{
La construcción cultural de la corporalidad femenina
}

\author{
Eugenia Zicavo ${ }^{1}$ \\ ezicavo@sociales.uba.ar
}

Un cuerpo no nace, se hace. La paráfrasis a la famosa frase de Simone De Beauvoir referida a la mujer no es azarosa, pero su alusión corre el riesgo que en nuestra sociedad enfrentan todas las corporalidades humanas: ser subsumidas a un producto, quedar ancladas en la pura forma; la estética que prescribe una ética. Nada aparenta ser más propio y "natural" que el cuerpo, y sin embargo no es más que el efecto de múltiples mediaciones (sociales, políticas, económicas, de género): el modo en que nos vemos es el resultado de un complejo proceso cultural. En el caso de los cuerpos de las mujeres, algunos ejes permiten iluminar el recorrido del modelo estético hegemónico hoy vigente en Occidente, que en la actualidad encuentra en los medios de comunicación masiva su mayor difusión y reproducción ideológica. Los modos sociales de procesar la imagen femenina también reflejan fenómenos de diversa índole que involucran pautas de seducción y cortejo, permisos o prohibiciones sexuales, cantidad de embarazos, criterios de salud, modelos de alimentación, cánones de belleza ${ }^{2}$.

Las convenciones sociales respecto a lo considerado deseable en materia estética se han ido modificando según los diferentes regímenes y períodos históricos pero, más allá de sus diferencias, compartieron una preocupación común: prescribir una "palabra oficial" sobre los cuerpos de las mujeres. Desde la medicina a los manuales de "buenas costumbres" pasando por los dictados de la moda, diversos discursos se disputaron la autoridad para describir y prescribir lo bello, ya sea respeto a los modales, el peso, la complexión y hasta la edad considerada "ideal". Todas las sociedades y culturas han tenido criterios estéticos sobre las corporalidades, identificando y valorando por sobre otras aquellas características consideradas deseables (e interviniendo a tal efecto para lograr cuerpos que se adecuen a ellas). Pero fue a partir de que el cuerpo femenino fue

\footnotetext{
1 Eugenia Zicavo es Doctora en Ciencias Sociales por la Universidad de Buenos Aires, docente e investigadora en el Instituto Gino Germani en la misma Facultad, becaria posdoctoral CONICET, Consejera Editorial de la Revista Lamujerdemivida.

2 Cabe aclarar que el impacto de los modelos estéticos circulantes varía entre las mujeres de los sectores medios y altos y las pertenecientes a los sectores populares. Si bien las mujeres de todos los sectores están expuestas a los mismos modelos corporales considerados legítimos, el imperativo de su reproducción es bastante más lábil en los sectores populares, en parte por falta de acceso al capital económico necesario que les permita una modelación del cuerpo en tanto bien simbólico.
} 
autorizado socialmente para mostrarse públicamente casi en su totalidad -un cambio cultural que se aceleró desde la década de 1960 hasta nuestros días- que pasó a ser objeto de un revisión exhaustiva: a cada parte del cuerpo, ahora potencialmente visible, se le añadió una prescripción. Un ejemplo de ello es la celulitis, una característica propia de la piel de las mujeres, visible especialmente en nalgas y glúteos. De hecho el significante "celulitis" fue acuñado recién entrado el siglo xx para designar a eso que antes no tenía nombre y que tampoco era "visto" -ni valorado negativamente- ya que durante siglos fue sólo eso: piel de mujer. Las ocasiones de que dichas partes del cuerpo quedaban bajo la mirada de los otros eran escasas y siempre en el ámbito estrictamente privado (si es que quedaban alguna vez al descubierto, porque también hubo épocas en las que los esposos consumaban el acto sexual pero mediados por camisas, con suerte con sendos agujeros hechos a medida). Pero la revolución sexual, con todo su arsenal de libertades y conquistas en materia de estéticas y derechos, no sólo liberó a los cuerpos de las rígidas normas sexuales que antes disciplinaban su deseo. También los dejó al descubierto en medio de un auge del capitalismo a nivel mundial que vio en esos cuerpos un nuevo territorio para su particularización y, en consecuencia, para montar sobre ellos un nuevo comercio: el de la belleza exhaustiva.

A partir de entonces, los cuerpos de las mujeres cobraron un protagonismo inédito en el mundo del cine, la publicidad, las revistas, la televisión. Los medios masivos de comunicación rápidamente advirtieron su potencial mercantil, no sólo para alentar con ellos deseos eróticos y vincularlos a otras mercancías sino para que pasaran a ser en sí mismos un objeto de deseo para las propias mujeres, mediante la industria de la belleza. Ellas mismas iban a querer aquello que les permitiera acercarse al ideal estético propuesto; comprando tratamientos, cremas, cirugías, ellas mismas se convertirían en su propia y mejorada "mercancía".

Los medios presentan al "cuerpo perfecto" 3 como posible de ser alcanzado mediante una creciente oferta de tratamientos de estética corporal (entre ellos las cirugías pero también novedades como la carboxiterapia, ultracavitación, mesoterapia, bótox, blanqueamiento dental, hydrofacial, permanente de pestañas, lifting sin cirugía, depilación definitiva, electrodos... y la lista sigue) que con la complicidad del aparato médico hegemónico, prometen eliminar la celulitis, el exceso de peso, las manchas en la piel y las marcas del paso del tiempo. La medicina absorbió la demanda de mujeres que, más allá de la atención de su salud, estaban cada vez más preocupadas por su apariencia física:

\footnotetext{
3 Aunque afectan primordialmente a las mujeres, estos modelos también influyen (más recientemente y en menor medida) en los varones. Si bien las imágenes ideales de belleza masculina se han modificado en los últimos años y también para ellos la delgadez y la juventud son horizontes a conquistar (el surgimiento de productos cosméticos y anti age para el mercado masculino es un ejemplo de ello) aún operan de manera menos imperativa, condicionando sus prácticas cotidianas en menor medida.
} 
los nuevos imperativos estéticos abrieron todo un nuevo mercado de la apariencia. De hecho, la presión de los nuevos cánones que impusieron culturalmente cuerpos cada vez más flacos modificó incluso ciertos criterios médicos de "salud", como las tablas de ta$\mathrm{lla} /$ peso que manejaban como parámetro de lozanía y que se adecuaron (adelgazando las correspondencias) al ser descartadas como palabra autorizada por las propias pacientes, que reclamaban para sí otra figura, fuera o no saludable.

Si la aparición de la píldora les permitió a las mujeres tener en sus manos la posibilidad de separar sexualidad de reproducción, la creciente industria cosmética -en alianza con la medicina- dejó en sus manos la responsabilidad de lograr, conservar o mejorar un cuerpo bello. Nada que, según la promesa propagada, no se pudiera lograr con algo de sacrificio, tiempo y dinero. En los inicios del siglo xxi podemos referirnos ya a una verdadera cultura de la belleza, con parámetros estéticos que resultan cada vez más prohibitivos, y cuya difusión mediática construye estándares y genera expectativas cada vez más irreales para la población femenina, con efectos tanto a nivel simbólico como material, por ejemplo en el ámbito de la salud. La escalada de trastornos alimenticios como la anorexia y la bulimia (que afectan principalmente a las mujeres) son el resultado de intentos desesperados por alcanzar un ideal de belleza que exige llevar al cuerpo a su mínimo peso, a su mínima expresión. Incluso en torno a dichas enfermedades ha surgido una subcultura juvenil, la de las adoradoras de Ana y Mia (anorexia y bulimia), autodenominadas princesas, que intercambian consejos y dietas por la web y que lo consideran un "modelo de vida", con máximas como "La comida es como el arte, está sólo para mirarla", "Me como a mî" o "Si no duele no funciona".

En la actualidad la imagen femenina cobró un protagonismo inusitado en los medios, como una suerte de garantía de "atractivo sensorial" para los consumidores frente a las páginas, afiches o pantallas que la reproducen. Pero no se trata de cualquier tipo de imagen corporal. Los códigos con que se percibe y procesa la apariencia física de las mujeres se han vuelto más particularizados y los criterios de lo bello cada vez más restrictivos, así como su representación mediática -con sus cuerpos "modelo"- ha amplificado la distancia con la mayoría de las corporalidades femeninas. Paulatinamente los contornos se fueron volviendo más visibles, las ropas más ligeras, y las prácticas para custodiar o mejorar el físico pasaron a ser más comunes y regulares. Pero nunca tantos discursos (desde tan variadas disciplinas) se han disputado el territorio del cuerpo femenino como en la actualidad. Y tampoco antes habíamos asistido a tal parcelamiento y particularización de dicho cuerpo, convertido en una sumatoria de islas, de detalles, de pequeñas partes a ser "revisadas" y, en lo posible, "mejoradas".

Dicho avance sobre el cuerpo no es inocente. Se trata de la contracara represiva de diversos procesos sociales emancipatorios que tuvieron y tienen a las mujeres como protagonistas y que encontraron en la difusión de estos modelos estéticos su dique de con- 
tención, su barrera a la autonomía. Al techo de cristal se le sumaron las tejas de la comida. Retomando las ideas de Naomi Wolf en El mito de la belleza, cuantas más libertades y derechos han obtenido las mujeres, más opresivas se han vuelto las imágenes legítimas que definen a la belleza femenina. En otros términos, en un momento histórico en el cual las mujeres han logrado como nunca antes conquistar posiciones de poder en la sociedad, más aumentó la presión social y la consecuente "necesidad" de que sus cuerpos se correspondan con el modelo idealizado, definido por atributos cada vez más difíciles de alcanzar. Esta "exigencia de belleza” puede definirse principalmente por dos características: la delgadez y la juventud (o al menos, su signo).

Este intento e interés por apropiarse del modelo propuesto por los medios no implica que no exista reflexividad por parte de las mujeres, pero la experiencia concreta en la vida social da cuenta de las ventajas que supone poseer una imagen corporal acorde a la socialmente legitimada, ya sea para ser más valoradas a nivel personal, laboral o sentimental. Y es aquí donde las distancias entre la fuerza de los mandatos estéticos para varones y mujeres se vuelven verdaderamente relevantes. El cuerpo (todos los cuerpos) es un producto social a través del cual se expresan ciertos códigos de la cultura. Y en los varones, otras cualidades siguen siendo igual o mayormente estimadas que la apariencia física. Por ejemplo, las mujeres destinan un plus significativo de tiempo a la "producción de belleza" (peinado, uñas, maquillaje, ropa y accesorios), un tiempo que desvían de otras atenciones, entre ellas las laborales, precisamente para llegar al trabajo "presentables" (y sabemos que la "buena presencia” no implica ni significa igual inversión para unos que para otras). Considerando que en términos históricos el ingreso de las mujeres al mundo del estudio, del trabajo, de la política y a la vida pública en general es sumamente reciente, portar un cuerpo que se acerque al modelo dominante implica poseer recursos que confieren cierto poder en los vínculos sociales, un capital distintivo que en las sociedades patriarcales aún se prioriza por sobre otras cualidades y características de la identidad personal.

Hoy los looks se han diversificado y distintas subculturas con sus estéticas particulares parecen convivir en armonía, pero sin embargo se trata de un "maquillaje de diversidad" que sólo logran portar de manera legítima las corporalidades hegemónicas, para las cuales la delgadez - principalmente- traza el límite entre lo dominante y lo subordinado. Pero también lo "delgado" es el resultado de una construcción social arbitraria cuyos parámetros se han modificado históricamente- que como categoría de percepción ha registrado un abrupto descenso de peso especialmente en las dos últimas décadas. Es decir, fueron cambiando los códigos con los que se percibe y procesa la belleza (en tanto bien valorado socialmente) y con ellos se fueron modificando los comportamientos, las prohibiciones y sanciones vinculadas al dominio sobre el cuerpo. Lo bello, que despliega un universo mercantil hacia su plena industrialización para su logro imaginario, ha ido afinando sus parámetros y restringiendo los contornos a ideales tan estrictos, que 
lo antes considerado bello y flaco ha dejado de serlo y distintas formas antes incluidas pasaron a integrar el grueso de los excluidos. En suma, hasta hace relativamente poco, pertenecer era más fácil: el ideal de belleza era más inclusivo. Hoy varias industrias (cosméticas, de cirugías, de tratamientos estéticos e incluso del deporte) se expanden gracias a que "la belleza", un atributo antes mayormente distribuido y con márgenes más flexibles, se ha convertido en un "bien escaso".

Los mensajes, imágenes y actitudes difundidas por los medios influyen en la manera en que las mujeres se sienten y se perciben a sí mismas, consolidando inhibiciones y expectativas que, cuando no atentan contra su salud, van lesionando su autonomía por imposición de parámetros externos (que sin embargo internalizan como propios), en torno a un "deber parecer" que las oprime. Además, todos estos discursos naturalizan el vínculo entre belleza y esfuerzo -cuando no directamente con el sufrimiento- minimizando sus consecuencias negativas (dolor posquirúrgico en las cirugías, resultados no alcanzados o peor aún, en absoluto satisfactorios) bajo un acuerdo tácito según el cual para ser bella hay que "soportar" y tener "disciplina". Es un ideal que, para ser alcanzado, precisa de cuerpos dóciles. Para ello hay que someterse a tratamientos, luchar contra las arrugas, tener conducta: los significantes asociados a lo que las mujeres deberían estar dispuestas a realizar con tal de alcanzar una figura valorada son bastante elocuentes. La belleza (ligada a la juventud pero también, independientemente de la edad, a la delgadez) aparece como mandato sustentado en la idea de que cada mujer es responsable de su propia imagen, que debe pasar a estar sometida a una constante auto-evaluación. Si antes las estrellas del cine y la televisión escondían sus cirugías, hoy cada vez más hablan de sus intervenciones, no ya como "confesión" sino como un triunfo (sobre las formas, sobre el paso del tiempo). Es la transparencia de un aparato mercantil que ha colonizado a las corporalidades y que proclama (y prescribe) una belleza "al alcance de todas" (las que puedan pagarlo, claro).

Así, el fracaso en la consecución de dicho ideal adopta otro sentido que deviene sentimiento de culpa y hasta de victimización, cuando en realidad ninguna de las intervenciones va a lograr satisfacer plenamente lo que cada subjetividad supo proyectar en ellas. Las mujeres se refieren a los motivos por los cuales se realizan tratamientos o cirugías estéticas aludiendo a que lo hacen para "ganar autoestima" o "sentirse más seguras", pero siempre el ideal estético va a estar un poco más allá. Aún más ahora, con la popularización de los programas para retocar las imágenes digitalmente, que hizo que el ideal de belleza tuviera su aufheben en la "estética del Photoshop", el trazo que permite borrar toda marca y corregir lo que ninguna cirugía lograría con tamaña precisión: una imagen totalmente maleable cuyo resultado final sólo tiene un vago referente en el mundo real.

Tanto los mensajes transmitidos por los medios de comunicación como el tipo de alimentación, el sector social de pertenencia, las condiciones de trabajo, la generación 
y el género suponen mediaciones sociales que producen a las diferentes corporalidades. La cultura condiciona, moldea y le da forma al cuerpo en tanto producto social. Como portador y productor de signos, el cuerpo habla y es hablado por las pautas culturales dentro de las cuales se lo reconoce como soporte de sentido: características como el volumen, la forma y el peso, así como las posturas que adopta o las ropas que viste, expresan la historia de su portador. Se trata de un cuerpo cargado de sentido.

El modelo de belleza para las mujeres (con vientres planos y piernas finísimas pero pechos y glúteos en lo posible lisos y prominentes y sin marcas del paso del tiempo) no responde en absoluto a la variedad y diversidad de las formas femeninas. Los cambios culturales en la percepción de lo bello y los mandatos sociales sobre la apariencia física derivados de ellos, implican un nivel de alienación respecto al ser genérico, que difundido por los aparatos de hegemonía se alza sobre la base de una industria que lo propone como ideal a conquistar. En este sentido, en su afán por alcanzar dicho modelo, las mujeres internalizan y reproducen ideales estéticos que dejan a sus propios cuerpos por fuera de lo considerado legítimo. En términos de Bourdieu, se trata de una adhesión visceral de un cuerpo socializado al cuerpo social que lo ha formado. Son ellas las que, habiendo incorporado las categorías dominantes, las reproducen en sus prácticas y en sus juicios. Incluso, aunque puedan ser críticas de dicho modelo, no pueden ver belleza "verdadera" en un cuerpo con "kilos de más": sus criterios de visión y división del mundo reproducen los criterios estéticos instalados. Son ellas las que principalmente conocen "lo que hay que comer" y "cómo comerlo" para "no engordar": un saber ganado a fuerza de socialización disciplinante en la cual son otras mujeres (madres, amigas, hermanas, compañeras de trabajo) las que señalan las "ilegalidades", los alimentos "prohibidos" o "permitidos", en una ecuación en la cual el descanso (los fines de semana, las vacaciones, los momentos exentos de obligaciones) termina relacionándose en el imaginario con el placer que proporciona comer sin restricciones.

Autores como Paula Sibilia o Georges Vigarello han analizado cómo en la denominada "sociedad del espectáculo" la apariencia corporal asume un valor fundamental en tanto imagen visible del sujeto, reduciéndose muchas veces su identidad a su presencia y su cuerpo a una suerte de "monopolio de la apariencia". Los códigos culturales vinculados a la socialización de género y los modelos difundidos por los medios intervienen en la construcción social de la belleza femenina incidiendo en los comportamientos de las mujeres, cuyas categorías clasificatorias, al naturalizarse, son compartidas y percibidas como legítimas. Al socializarse en esta cultura de la estética, las mujeres terminan incorporando como "naturales" modelos de belleza que en realidad son producto de una lucha por la imposición social del sentido (y, por lo tanto, pasibles de ser cuestionados y modificados).

El cuerpo femenino se encuentra objetivado a partir de una mirada social que lo sopesa, clasifica y valora de acuerdo a la distancia que mantiene, en tanto cuerpo particular, 
con el ideal del modelo dominante. Esta interiorización de esquemas de percepción opresivos resulta en una gran disconformidad con respecto al propio cuerpo, incluso aunque la "artificialidad" y la "producción" de las corporalidades consideradas legítimas queden cada vez más en evidencia. Estas representaciones no son incorporadas necesariamente de manera pasiva y acrítica por parte de las mujeres; pueden reconocer lo arbitrario del modelo instalado y la distancia entre cómo opera el imperativo estético para las mujeres y los varones (siempre más variado y permisivo con éstos últimos, tanto en materia de edades como de formas corporales) pero dicho modelo continúa siendo un parámetro de comparación con el propio cuerpo: un ideal criticado pero también deseado y admirado. 